\title{
Association between the Use of Alternative Medicine and Adherence to Treatment in Patients with Type 2 Diabetes
}

\author{
Perez-Sosa Abigail $\mathbf{M}^{1 *}$, Gregorio $\mathbf{P R}^{2}$ and Soto- \\ Pena Sonia $\mathbf{A}^{1}$ \\ ${ }^{1}$ Department of Family Medicine, Family Medicine Unit \\ \#46 (IMSS), Mexico \\ ${ }^{2}$ Department of Family Medicine, Family Medicine Unit \\ \#48 (IMSS), Mexico \\ *Corresponding author: Perez-Sosa Abigail Melissa, \\ Department of Family Medicine, Family Medicine Unit \\ \#46 (IMSS), Chihuahua Delegation, Mexico
}

Received: March 02, 2021; Accepted: April 14, 2021; Published: April 21, 2021

\begin{abstract}
Background: Diabetes mellitus 2 (T2D) is the leading cause of morbidity and mortality in northern Mexico. Various treatments are used to control the disease; however, the cost of these and the difficulty of dietary management have as a consequence that the patient abandons them and looks for cheaper and easier-to-use alternatives.
\end{abstract}

Aim: The purpose of this study is to determine the relationship between the use of alternative medicine and adherence to medical treatment in patients with T2D.

\section{Design and Setting: Analytic cross-sectional study.}

Methods: An analytical cross-sectional study was designed between March and July 2019 including 464 patients with T2D from the family medicine unit \#48 Ciudad Juarez, Mexico. We used the Morisky-Green scale for adherence to treatment and the use of Alternative Medicine (CAM) was evaluated with a holistic complementary and alternative medicine questionnaire. The Chi-Square test was used for comparison of proportions and risk factors were calculated using odds ratio with $95 \%$ confidence intervals.

Results: $53 \%$ of patients use CAM; biological therapy (herbs and supplements) is the most frequent (94\%). The association between CAM use and adherence to medical treatment was $2.1(95 \% \mathrm{Cl} 1.4-3.1, \mathrm{p}=0.001)$. The risk factors for the use of CAM were female sex, basic level education, uncontrolled disease and a time of evolution greater than 10 years.

Conclusion: CAM users are 2.1 times more at risk of having a regular or bad adherence to medical treatment.

Keywords: Alternative medicine; Adherence to treatment; Diabetes mellitus

\section{Introduction}

Diabetes is the leading cause of morbidity and mortality in northern Mexico [1]. Various treatments are used in its control, but their cost and the difficulty of dietary management cause the patient to seek other alternatives, which generates a poor adherence to medical treatment [2-3]. It is estimated that adherence to treatment in patients with T2D is around 60\% [4]. The World Health Organization (WHO) identifies five causal factors for which patients do not adhere to treatment, among which are variables related to the patient, treatment, health system, disease, and the socioeconomic variables. Diabetes patients are 1.6 times more likely to use alternative medicine (CAM) than non-diabetic patients [6].

Adherence to treatment is defined as that behavior of the patient that coincides with the prescribed medical indication in relation to the form and times of administration of medications, diet and changes in lifestyle [7]. CAM is defined as a diverse care system, practices and products that are generally not considered part of conventional medicine [8]. CAM is subdivided into five categories: 1) biological therapies: herbs and dietary supplements; 2) alternative medical systems: acupuncture; 3 ) systems based on manipulation of the body: chiropractors; 4) mind body interventions: taichi or yoga and 5) energy therapies: reiki [9]. Due to the above, the main objective of this research was to determine the relationship between the use of alternative medicine and adherence to medical treatment in patients with T2D and to determine the sociodemographic characteristics of CAM users, the degree of adherence to medical treatment and glycemic control.

\section{Material and Methods}

\section{Study design and population}

A descriptive, cross-sectional, analytical study was designed at FMU 48 Ciudad Juarez, Mexico; between March and July 2019. Patients with T2D of legal age, both sex and who agreed to participate in the study were included; those that did not have recent paraclinical studies or incomplete information were eliminated. All included patients signed an informed consent letter.

\section{Variables}

The evaluation of adherence to treatment was with the MoriskyGreen scale ( $8=$ High, $6-7=$ Medium and $<6=$ Low $)$ and the use of CAM was evaluated with a holistic questionnaire of complementary and alternative medicine $(>33=$ Yes, $<33=$ No), the scales were answered by the participants.
J Fam Med - Volume 8 Issue 3 - 2021

ISSN : 2380-0658 | www.austinpublishing group.com

Perez-Sosa Abigail et al. (C) All rights are reserved
Citation: Perez-Sosa Abigail M, Gregorio PR and Soto-Pena Sonia A. Association between the Use of Alternative Medicine and Adherence to Treatment in Patients with Type 2 Diabetes. J Fam Med. 2021; 8(3): 1247. 
Table 1: Sociodemographic characteristics of patients with T2D.

\begin{tabular}{|c|c|}
\hline Characteristic & n (\%) \\
\hline \multicolumn{2}{|l|}{ Sex } \\
\hline Female & $300(64.7)$ \\
\hline Male & 164 (35.3) \\
\hline \multicolumn{2}{|l|}{ Age } \\
\hline $21-35$ & $11(2.4)$ \\
\hline $36-50$ & 107 (23.1) \\
\hline $51-65$ & 207 (44.6) \\
\hline $66-80$ & 125 (26.9) \\
\hline $81-95$ & $13(2.8)$ \\
\hline$\geq 96$ & $1(0.2)$ \\
\hline \multicolumn{2}{|l|}{ Marital Status } \\
\hline Single & $34(7.3)$ \\
\hline Married & 343 (73.69) \\
\hline Cohabitation & $34(7.3)$ \\
\hline Divorced & $8(1.7)$ \\
\hline Separated & $8(1.7)$ \\
\hline Widowed & 37 (8) \\
\hline \multicolumn{2}{|l|}{ Education } \\
\hline Illiterate & $9(1.9)$ \\
\hline Primary & $233(50.2)$ \\
\hline Secondary & $139(30)$ \\
\hline Technique & $31(6.7)$ \\
\hline High school & $38(8.2)$ \\
\hline University & $14(3)$ \\
\hline \multicolumn{2}{|l|}{ Occupation } \\
\hline Operator & $130(28)$ \\
\hline House & $127(27.4)$ \\
\hline Retired & $122(26.3)$ \\
\hline Merchant & $19(4.1)$ \\
\hline Others & 66 (14.2) \\
\hline
\end{tabular}

\section{n: Frequency; \%: Percentage}

\section{Statistical analysis}

Measures of central tendency and percentages were used for the sociodemographic variables. Also, the Chi-Square test for comparison of proportions; risk factors were calculated using odds ratios and their $95 \%$ confidence intervals.

\section{Ethics}

This study was authorized by the Local Health Committee (CLIES 802) with registration number R-2019-802-021. The research was carried out in accordance with the Regulations of the General Health Law on Research for Health, the Declaration of Helsinki and the Bioethical Principles.

\section{Results}

488 patients were recruited, of which 24 were eliminated, 22 for not having recent paraclinical tests and 2 for complete information. A total of 464 patients were studied whose sociodemographic
Table 2: Association between the use of alternative medicine and adherence to medical treatment.

\begin{tabular}{|c|c|c|c|c|c|}
\hline \multicolumn{6}{|c|}{ Adherence to medical treatment } \\
\hline \multirow{2}{*}{ Characteristic } & Good & Regular & \multirow{2}{*}{ OR } & \multirow{2}{*}{$\mathrm{Cl} 95 \%$} & \multirow{2}{*}{$\mathbf{p}^{*}$} \\
\hline & n (\%) & n (\%) & & & \\
\hline \multirow{2}{*}{ With CAM } & 107 & 113 & \multirow{2}{*}{0.46} & \multirow{2}{*}{$0.314-0.672$} & \multirow{2}{*}{0.001} \\
\hline & -59.1 & -39.9 & & & \\
\hline \multirow{2}{*}{ Without CAM } & 74 & 170 & \multirow{2}{*}{2.175} & \multirow{2}{*}{$1.488-3.181$} & \multirow{2}{*}{0.001} \\
\hline & -40.9 & -60.1 & & & \\
\hline
\end{tabular}

n: Frequency; \%: Percentage; OR: Odds Ratio; p*: Chi-Square

Table 3: Analysis of risk factors associated with the use of alternative medicine in patients with $T 2 D$.

\begin{tabular}{|c|c|c|c|c|c|}
\hline \multicolumn{6}{|c|}{ CAM } \\
\hline \multirow{2}{*}{ Characteristic } & Yes & No & \multirow{2}{*}{ OR } & \multirow{2}{*}{ Cl $95 \%$} & \multirow{2}{*}{$\mathbf{p}$} \\
\hline & n (\%) & n (\%) & & & \\
\hline \multicolumn{6}{|c|}{ Age } \\
\hline$<65$ & $180(73.8)$ & $145(65.9)$ & 1.455 & $0.976-2.168$ & \multirow{2}{*}{0.065} \\
\hline$>65$ & $64(26.2)$ & 75 (34.1) & 0.687 & $0.461-1.024$ & \\
\hline \multicolumn{6}{|c|}{ Education } \\
\hline Basic & $209(85.7)$ & $172(78.2)$ & 1.666 & $1.031-2.693$ & \multirow{2}{*}{0.036} \\
\hline No basic & 35 (14.3) & $48(21.8)$ & 0.6 & 0.371-0.970 & \\
\hline \multicolumn{6}{|c|}{ Glycemic control } \\
\hline Controlled & $99(40.6)$ & $117(53.2)$ & 0.601 & $0.416-0.868$ & \multirow{2}{*}{0.007} \\
\hline Uncontrolled & $145(59.4)$ & $103(46.8)$ & 1.664 & $1.151-2.404$ & \\
\hline \multicolumn{6}{|c|}{ Hypercholesterolemia } \\
\hline Yes & $120(49.2)$ & $102(46.4)$ & 1.12 & $0.777-1.613$ & \multirow{2}{*}{0.544} \\
\hline No & $124(50.8)$ & $118(53.6)$ & 0.893 & $0.620-1.287$ & \\
\hline \multicolumn{6}{|c|}{ Hypertriglyceridemia } \\
\hline Yes & $150(61.5)$ & $118(53.6)$ & 1.379 & 0.953-1.996 & \multirow{2}{*}{0.088} \\
\hline No & $94(38.5)$ & $102(46.4)$ & 0.725 & 0.501-1.049 & \\
\hline \multicolumn{6}{|c|}{ Body Mass Index } \\
\hline$<24.9$ & $17(7)$ & $23(10.5)$ & 0.641 & $0.333-1.235$ & \multirow{2}{*}{0.181} \\
\hline$>25$ & $227(93)$ & $197(89.5)$ & 1.559 & $0.810-3.002$ & \\
\hline \multicolumn{6}{|c|}{ Sex } \\
\hline Male & $71(29.1)$ & $93(42.3)$ & 0.56 & $0.382-0.823$ & \multirow{2}{*}{0.003} \\
\hline Female & $173(70.9)$ & $127(57.7)$ & 1.784 & $1.215-2.621$ & \\
\hline \multicolumn{6}{|c|}{ Time of diagnosis } \\
\hline$<10$ years & $118(48.4)$ & $156(70.9)$ & 0.384 & $0.262-0.564$ & \multirow{2}{*}{0.001} \\
\hline$>10$ years & $126(51.6)$ & $64(29.1)$ & 2.603 & $1.772-3.822$ & \\
\hline
\end{tabular}

CAM: Alternative Medicine; $n=$ Frequency; \%: percentage; OR: Odds Ratio; $p$ : Chi-square

characteristics were: mean age 58.5 years (range 26-96), female sex $64.7 \%$, industry operator occupation $28 \%$, marital status married $73.9 \%$ and primary education $50.2 \%$ (Table 1 ). In relation to $\mathrm{T} 2 \mathrm{D}$, the most frequent evolution time was less than 5 years with $33.2 \%$. The most frequently associated comorbidity was systemic arterial hypertension (51.7\%) and uncontrolled blood glucose in $53.4 \%$ of the cases. Regarding adherence to medical treatment, it was found that only $39 \%$ of the participants had good adherence to treatment, $61 \%$ fair or poor. Of the total number of patients, $52.6 \%$ admitted the 
use of CAM, biological therapy was used more frequently (94\%). The odds ratio was calculated to evaluate the association between the use of CAM and adherence to medical treatment, obtaining a value of 2.1 (95\% CI 1.4-3.1, $\mathrm{p}=0.001$ ) (Table 2). The risk factors for the use of CAM were also analyzed, among which the basic level schooling with $\mathrm{OR}=1.6$ (95\% CI 1.0-2.6, $\mathrm{p}=0.036)$, uncontrolled blood glucose $\mathrm{OR}=1.6(95 \% \mathrm{CI} 1.1-2.4, \mathrm{p}=0.007)$, female gender $\mathrm{OR}=1.7(95 \% \mathrm{CI}$ $1.2-2.6, \mathrm{p}=0.003)$ and evolution of the disease over 10 years $\mathrm{OR}=2.6$ (95\% CI 1.7-3.8, $\mathrm{p}=0.001$ ) (Table 3).

\section{Discussion and Conclusion}

T2D and its complications represent a major publichealth problem. Treatment is the basis for the control of this condition; however, there are major defects in disease control and treatment strategies [10]. The results of this study show a negative association between the use of CAM and adherence to medical treatment. This finding is similar to that obtained by Alfian et al. where they demonstrated that the use of CAM decreases adherence to medical treatment in patients with T2D [11]. The uncontrolled disease reported in the 2016 National Health and Nutrition Survey was $68.2 \%$, which differs from what was found in this research with 53.4\%; however, these reflect the failures in the management and control of the disease, as well as the need to improve and renew existing strategies to ensure that patients with this condition receive full benefit with the approach provided [12-13]

According to Grandy et al. adherence to medical treatment of patients with T2D is $60 \%$ or less [2], a result that differs from what was obtained in this study where the degree of adherence reached only the $40 \%$; however, this difference could be explained because the characteristics of the populations studied are different. Atinga et al. in a population of a developing country, it was observed that therapeutic adherence was $38.5 \%$ where the main factors that hinder adherence to treatment were polypharmacy, socially accepted norms, perception of little effectiveness of the medications, as well as lack of medical instruction [14]. These results are more closely related to the reality of the health system in which this research was carried out. No studies were found that assessed risk factors for the use of CAM. In this research, an association was determined between the degree of schooling, uncontrolled disease, female sex and time of evolution of the disease with the risk of using these therapies, so it is important that the family doctor identifies these factors in order to intervene in a timely manner. The use of alternative medicine negatively affects adherence to medical treatment in patients with T2D. Therefore, it is important to identify risk factors for its use and achieve adequate metabolic control for prevent early complications in these patients.

\section{References}

1. Soto-Estrada G, Moreno-Altamirano L, Pahua-Díaz D. Panorama epidemiológico de México, principales causas de morbilidad y mortalidad. Rev Fac Med. 2016; 59: 1-4.

2. Moral J, Alejandra M. Predictores psicosociales de adherencia a la medicación en pacientes con diabetes tipo 2. Rev Iber Psicol y Sal. 2015; 6.

3. Mediavilla J. Factores asociados con la adherencia a la medicación en las personas con diabetes tipo 2. Diabet Med. 2015; 32.

4. Grandy S, Fox K, Hardy E. Association of Weight Loss and Medication Adherence Among Adults with Type 2 Diabetes: SHIELD (Study to Help Improve Early evaluation and management of risk factors Leading to Diabetes). Current Therapeutic Research. 2013; 75.

5. Orozco D, Mata M, Artola S, Conthe P, Mediavilla J, Miranda C. Abordaje de la adherencia en diabetes mellitus tipo 2: situación actual y propuesta de posibles soluciones. Aten Prim. 2016; 48: 12-19.

6. Necyk C, Zuback-Cassano L. Natural Health Products and Diabetes: A Practical Review. Can J Diabetes. 2017; 41.

7. Amezcua A, Rodríguez F, Díaz E. Apego al tratamiento y control de los pacientes diabéticos en la comunidad. Med Int Méx. 2015; 31.

8. Simoes-Wust A, Rist L, Dettling M. Self-Reported Health Characteristics and Medication Consumption by CAM Users and Non Users: A Swiss CrossSectional Survey. Journal Altern Compl Med. 2017; 20: 12-19.

9. Ching S, Zakaria Z, Paimin F, Jalalian M. Complementary Alternative Medicine Use Among Patients with Type 2 Diabetes in the Primary Care Settings: A Cross-Sectional Study in Malasya. BMC. 2013; 13: 148.

10. Camarillo G, López R, Morales J, Flores C, Demenegui V, Sergio G. Apego al tratamiento en pacientes diabéticos y sus creencias. UVserva. 2019; 2: 5-9.

11. Alfian S, Sukandar H, Arisanti N, Abdulah R. Complementary and alternative medicine use decreases adherence to prescribed medication in diabetes patients. Annals Trop Med and Pub Health. 2016; 9.

12. Basto-Abreu A, Barrientos-Gutiérrez T, Rojas-Martínez R, Aguilar-Salinas C, López-Olmedo N, De la Cruz-Góngora V, et al. Prevalencia de diabetes y descontrol glucémico en México: Resultados de ENSANUT 2016. Salud Pública Mex. 2020; 62.

13. Gutiérrez J, Rivera J, Shamah T, Villalpando S, Franco A, Cuevas L, et al. Encuesta Nacional de Salud y Nutrición 2012. Resultados Nacionales. $1^{\text {st }}$ ed. Cuernavaca, México: Instituto Nacional de Salud Pública. 2012.

14. Atinga R, Yarney L, Minta N. Factors influencing long-term medication nonadherence among diabetes and hypertensive patients in Ghana: A qualitative investigation. PLoS One. 2018; 13. 